\title{
Passive Reactor Compensated Cascaded H-Bridge Multilevel LC-StatCom
}

\author{
Farivar, Glen; Townsend, Christopher David; Hredzak, Branislav; Pou, Josep; Agelidis, Vassilios
}

Published in:

IEEE Transactions on Power Electronics

Link to article, DOI:

10.1109/TPEL.2016.2641043

Publication date:

2017

Document Version

Peer reviewed version

Link back to DTU Orbit

\section{Citation (APA):}

Farivar, G., Townsend, C. D., Hredzak, B., Pou, J., \& Agelidis, V. (2017). Passive Reactor Compensated Cascaded H-Bridge Multilevel LC-StatCom. IEEE Transactions on Power Electronics, 32(11), 8338 - 8348. https://doi.org/10.1109/TPEL.2016.2641043

\section{General rights}

Copyright and moral rights for the publications made accessible in the public portal are retained by the authors and/or other copyright owners and it is a condition of accessing publications that users recognise and abide by the legal requirements associated with these rights.

- Users may download and print one copy of any publication from the public portal for the purpose of private study or research.

- You may not further distribute the material or use it for any profit-making activity or commercial gain

- You may freely distribute the URL identifying the publication in the public portal 


\section{Passive Reactor Compensated Cascaded H-Bridge Multilevel LC-StatCom}

Article in IEEE Transactions on Power Electronics · December 2016

DOI: 10.1109/TPEL.2016.2641043

CITATIONS

4

5 authors, including:

Chris Townsend

Nanyang Technological University

52 PUBLICATIONS 461 CITATIONS

SEE PROFILE

2. J.Pou

12 Nanyang Technological University

195 PUBLICATIONS $\quad \mathbf{6 , 0 2 7}$ CITATIONS

SEE PROFILE

Branislav Hredzak

UNSW Sydney

100 PUBLICATIONS $\mathbf{1 , 1 1 2}$ CITATIONS

SEE PROFILE

(3) Vassilios Georgios Agelidis

Technical University of Denmark

467 PUBLICATIONS $\quad \mathbf{9 , 4 6 0}$ CITATIONS

SEE PROFILE

Some of the authors of this publication are also working on these related projects:

Efficient Micro Drives for small scale Drones and micro EV View project

Modulation of Modular Multilevel Converters View project 


\title{
Passive Reactor Compensated Cascaded H-Bridge Multilevel LC-StatCom
}

\author{
Glen Farivar, Student Member, IEEE, Christopher D. Townsend, Member, IEEE, Branislav Hredzak, \\ Senior Member, IEEE, Josep Pou, Fellow, IEEE, Vassilios G. Agelidis, Fellow, IEEE
}

\begin{abstract}
The cascaded H-bridge (CHB) low-capacitance StatCom (LC-StatCom) has a limited operating area in the inductive region compared to a conventional StatCom's V-I characteristic. This limitation for operation in the inductive region is considered to be the biggest disadvantage of CHB LCStatCom. In this paper, the effect of adding parallel and series reactors on the LC-StatCom system's $V$-I characteristic is analyzed. Then, a new configuration, which fully compensates for the lost operating area of the LC-StatCom is introduced. A scaled down single-phase seven-level laboratory prototype is used to confirm practicability of the proposed system.
\end{abstract}

Index Terms - Cascaded H-bridge, LC-StatCom, reactive power compensation, thin dc capacitor

\section{INTRODUCTION}

$\mathrm{T}$ HE cascaded H-bridge multilevel converter (CHB-MC) is a popular choice in many industrial applications due to its modularity, ability to decrease switching loss while maintaining excellent harmonic performance, and the possibility to eliminate the step-up transformer in medium voltage applications [1], [2]. An additional feature which makes this converter suitable for the StatCom application is its linear relationship between level number and component count [2], as opposed to monolithic multilevel converters where this relationship is quadratic.

Compared to monolithic multilevel converters, the requirement for isolated dc power sources is considered to be one of the main disadvantages [1]. However, in StatCom applications the isolated dc sources are floating capacitors and therefore the isolation requirement is easily met. The idea of using a CHB-MC as a StatCom was introduced in [3]. Thereafter, different aspects of this application for CHB-MC

This manuscript was submitted for review in August 25, 2016, revised in October 24, 2016, accepted in November 29, 2016.

Glen Farivar and Branislav Hredzak are with the school of electrical engineering and telecommunication at the University of New South Wales (UNSW Australia), Sydney, NSW 2052 Australia (e-mails: g.farivar@unsw.edu.au,b.hredzak@unsw.edu.au).

Christopher Townsend is with the University of Newcastle, School of Electrical Engineering and Computer Science, Australia (townsend@ieee.org,).

Josep Pou is with Nanyang Technological University, School of Electrical and Electronic Engineering, Singapore 639798 (E-mail: j.pou@ntu.edu.sg)

Vassilios G. Agelidis is with Technical University of Denmark, Department of Electrical Engineering, 2800 Kgs. Lyngby, DENMARK (email: vasagel@elektro.dtu.dk) have been studied in the technical literature [4]-[24].

A three-phase CHB converter is constructed from three single-phase converters, which implies that each phase-leg must buffer the per-phase variations in instantaneous power that occur within each fundamental cycle. Typically, the voltage variation on the capacitors due to flow of this instantaneous power is limited to less than $10 \%$ of nominal dc voltage [31] by utilizing large dc capacitors. The need for large capacitors increases the cost, weight, and volume of the system. Furthermore, utilizing electrolytic capacitors to achieve the required high capacitance reduces the reliability of the system [25], [26].

Recent studies demonstrated the feasibility of operating CHB StatCom with low capacitor sizes, implying operation with capacitor voltage ripples in excess of the conventional 10\%. In [33], a CHB StatCom was developed that was able to operate with approximately $30 \%$ voltage ripple on the capacitors. The system was constructed using film capacitors to achieve high reliability [27]-[30]. Reduced capacitor size requires a faster control system to regulate capacitor voltages during transient conditions. Simultaneously, removing the effect of voltage ripple components on the controller becomes more challenging due to the increased size of the ripple. To address these issues, the control system in [33] utilizes an analytic formula to eliminate the ripple component from each measured cluster voltage (sum of capacitor voltages in a phase-leg) without imposing any significant delay into the control loop.

In a conventional CHB StatCom, the minimum cluster voltage is designed to be at all times higher than the sum of peak grid voltage and peak voltage drop across the connection inductor. As a consequence, in conventional CHB StatComs, increasing the ripple on capacitors causes increased peak cluster voltages, which is a major limiting factor for reducing the capacitor energy and size. Larger peak cluster voltages were also the main disadvantage of the system developed in [33].

In [34], the CHB low capacitance StatCom (LC-StatCom) concept was developed. In the CHB LC-StatCom the desire to minimize H-bridge capacitances is achieved by restricting the $V-I$ operating characteristic of the converter. In theory, the LCStatCom system is able to operate with $100 \%$ ripple on the capacitors and facilitate lower peak capacitor/cluster voltages compared to a conventional CHB StatCom. It was shown that when operating in the capacitive region, the synthesized output voltage waveform has the same phase angle as the 
capacitor voltage ripple waveform. This implies there is sufficient cluster voltage to maintain current control even when the cluster voltage reduces to almost zero. Hence, the CHB LC-StatCom is a promising solution for significantly reducing $\mathrm{H}$-bridge capacitance values. Furthermore, better voltage and current quality, lower voltage stress on switches and lower switching losses are additional benefits of the LCStatCom [34]. However, the limited V-I operating capability is the main disadvantage.

In this paper, a passive reactive compensated LC-StatCom system, which integrates the concept of a thyristor bypassed reactor (TBR), is proposed to overcome the abovementioned shortcoming of the LC-StatCom. In a TBR device, thyristor switches are connected in parallel to the inductor. Therefore, this concept differs from the conventional thyristor controlled reactors (TCR) where the switches are placed in series with the inductor. The proposed compensated LC-StatCom system maintains the benefits of the LC-StatCom while reshaping its $V-I$ characteristics to match a conventional StatCom.

The rest of this paper is organized as follows. Section II provides the background on the CHB LC-StatCom system. The effect of series and parallel reactors on the $V-I$ characteristics of the LC-StatCom system is analyzed in Section III. The proposed compensated LC-StatCom system is introduced in Section IV. Experimental results are provided in Section V. Finally, conclusions from the work are summarized in Section VI.

\section{CHB LC-STATCOM SYSTEM}

\section{A. CHB LC-StatCom Model}

Fig. 1 shows a single-phase CHB LC-StatCom. A threephase configuration is composed of three identical singlephase converters. Therefore, for the rest of this paper, without loss of generality, a single-phase system is considered.

Using Kirchhoff's voltage law on the ac side yields,

$\sum_{j=1}^{N} v_{j}-v_{g}-R i_{g}-L \frac{d i_{g}}{d t}=0$

where, $v_{j}$ is the ac voltage generated by the $j^{\text {th }}$ H-bridge $(j \in\{1, \ldots, N\}), L$ represents the filter inductor and $R$ is its parasitic series resistance. $v_{g}$ and $i_{g}$ are the grid voltage and converter current, respectively.

On the other hand, on the dc side of each H-bridge,

$i_{C-j}+C \frac{d v_{c-j}}{d t}=0$

where $C$ represents the capacitance of the capacitors $\left(C=C_{l}=C_{2}=\ldots=C_{N}\right)$ and $v_{c-j}$ is the voltage across the individual capacitors. $i_{C-j}$ represents the current flowing into the $j^{\text {th }}$ capacitor. Assuming that the losses are negligible, the input power on the ac side is equal to the output power on the dc side; hence,
H-Bridge 1
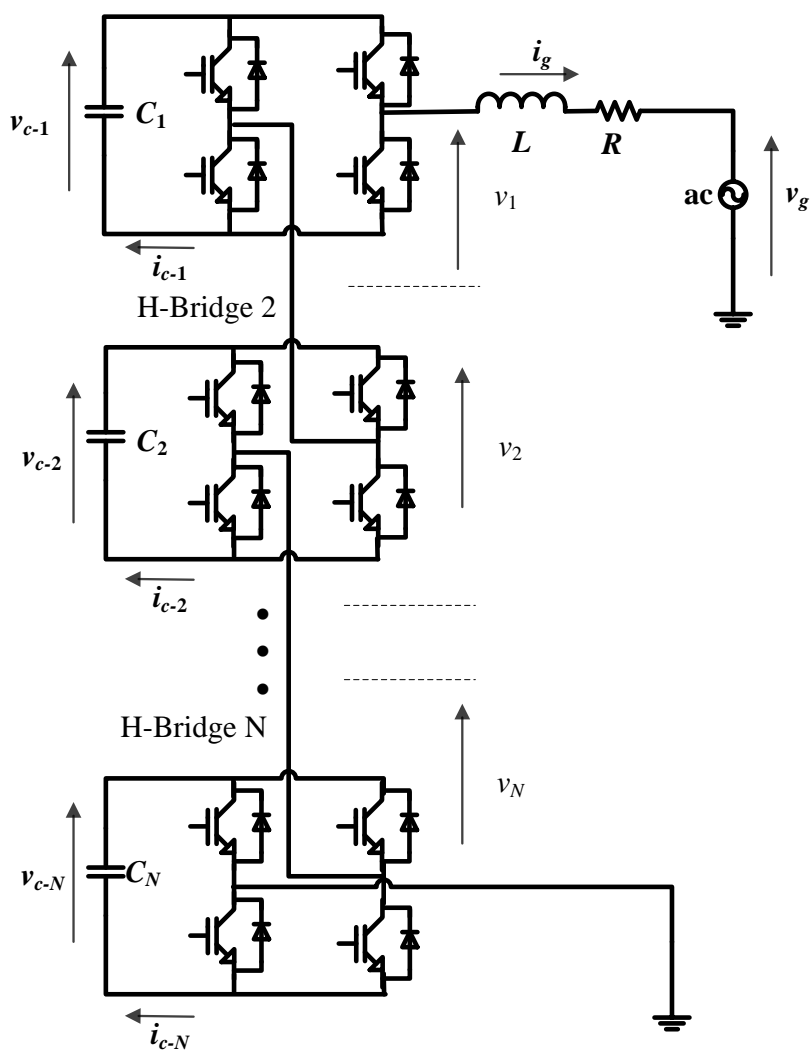

Fig. 1. A general single-phase, (2N+1)-level CHB converter StatCom

$i_{C-j}=\frac{v_{j}}{v_{c-j}} i_{g}$

Replacing $i_{c-j}$ from (3) in (2) yields,

$\frac{v_{j}}{v_{c-j}} i_{g}+C \frac{d v_{c-j}}{d t}=0$

(1) and (4) are the core equations that model the behavior of the $\mathrm{CHB}$ converter.

\section{B. Control System}

From a hardware perspective, except for facilitating smaller H-bridge capacitance values, the CHB LC-StatCom is similar to a conventional CHB StatCom, as can be seen from Fig. 1. However, the control system must operate differently due to the low capacitances and large voltage ripples on the capacitors. The overall view of the utilized control system is shown in Fig. 2 [34].

The individual capacitor voltage loops use separate PI controllers to balance the voltage on each capacitor [35]. The current is controlled by a dead-beat controller to achieve fast dynamic performance. The cluster voltage controller uses the square of the voltage to linearize the control system, which is important as the voltage reference varies throughout a wide range, implying the nonlinear relationship between voltage and capacitor energy would otherwise cause significant control interaction between loops [35]. The feedforward ripple 


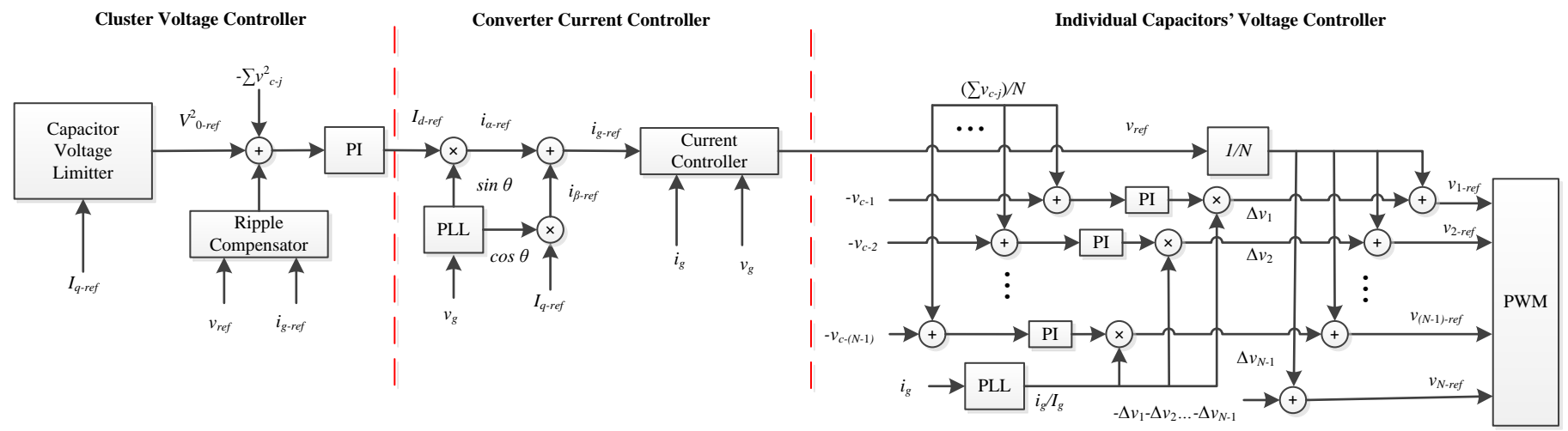

Fig. 2. LC-StatCom control system composed of three sub-sections: (i) cluster voltage controller, (ii) current controller, and (iii) voltage balancing (individual capacitors' voltage controller).

compensator subtracts the second order ripple component from the measured capacitor voltages. The ripple compensator replaces the low pass filter typically utilized in conventional controllers [10], and allows an increase in the bandwidth of the cluster voltage controller.

The LC-StatCom is well suited to operate in capacitive region as the ripple on the capacitor voltages is in phase with the grid voltage, which allows the control system to lower the cluster reference voltage well below the peak grid voltage. Fig. 3 shows the operational principal of the LC-StatCom compared to a conventional CHB StatCom. The LCStatCom's ability to operate with capacitor voltages lower than the grid voltage peak, provides the control system with a degree of freedom to maintain a fixed maximum voltage on the capacitors, $V_{d c-\max }$, when the ripple is large (as high as $90 \%$ of the nominal dc capacitor voltage). The LC-StatCom control system uses a capacitor voltage limiter (CVL) module to generate a reference signal for the cluster voltage controller [34]. The operation principal of the CVL is provided in the Appendix.

\section{Passive Reactive Compensation}

It was shown in [34] that the operational limits of an ideal LC-StatCom are as follows

Capacitive:

$\left(0 \leq I_{q(p . u)} \leq 1\right) \quad, \quad\left(0 \leq V_{g(p . u)} \leq 1\right)$.

Inductive:

$$
\begin{array}{ll}
0<I_{q(p . u)} \leq \frac{1}{V_{g(p . u)}}-V_{g(p . u)} & , \quad\left(0.62 \leq V_{g(p . u)} \leq 1\right) \\
0<I_{q(p . u)} \leq 1 & , \quad\left(0 \leq V_{g(p . u)}<0.62\right)
\end{array}
$$

The details and the assumptions to derive these limits are provided in the Appendix. It is worthwhile mentioning that to simplify the comparison between compensation options; the rest of this section considers an ideal case. That is, the effect of series filtering inductor $\left(L_{f}\right)$, included in any StatCom voltage source converter to facilitate current control, is

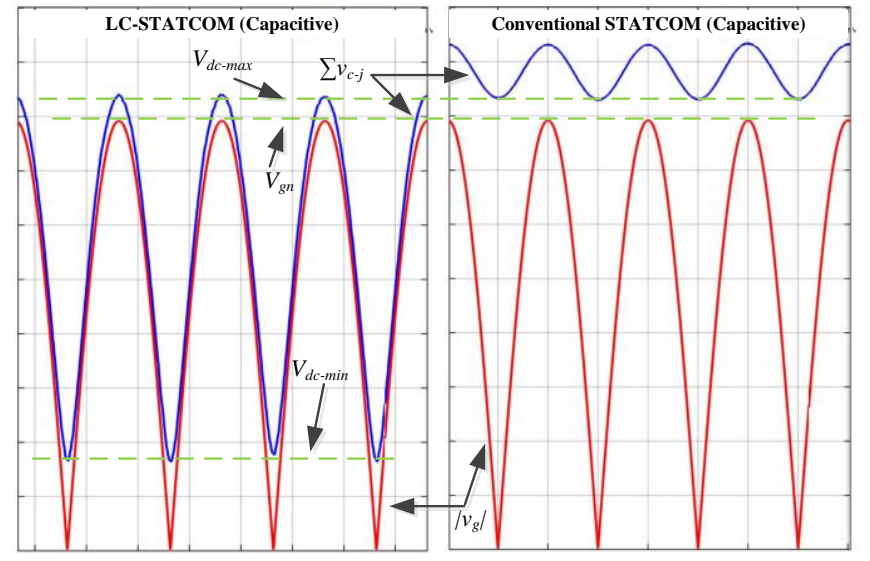

(a)

(b)

Fig. 3. Comparison between operation of (a) LC-StatCom system and (b) conventional StatCom system.

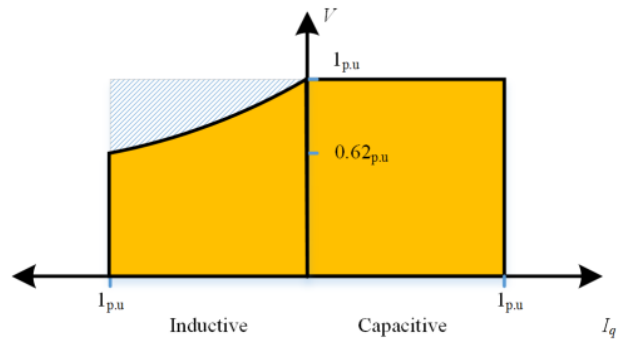

Fig. 4. V-I characteristics of an LC-StatCom.

neglected. The effect of this inductor on the I-V characteristic will be addressed in Section V. The operational limits defined in (5) and (6) are shown graphically in Fig. 4 by the solid black lines. Therefore, the dashed area shown in Fig. 4 needs to be added to the V-I characteristic of the LC-StatCom, in order to compensate for its shortcoming compared to a conventional StatCom.

To expand the inductive operating region, a compensating inductor can be added to the LC-StatCom in either parallel or series configurations as shown in Fig. 5. If utilizing a parallel compensation inductor, the disconnecting switch, $S_{p}$, needs to be closed when the LC-StatCom operates in the inductive region. Alternatively, if utilizing a series compensation 


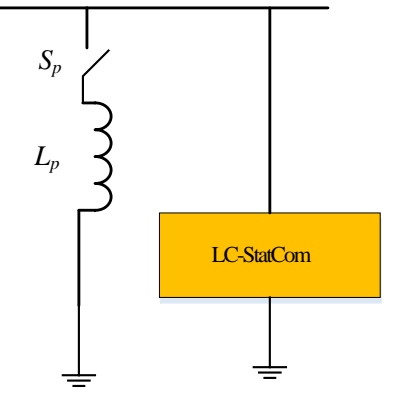

(a)

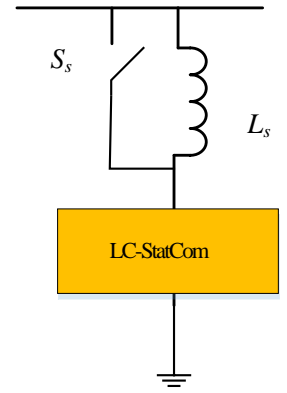

(b)
Fig. 5. Integrating a compensating inductor into an LC-StatCom system. (a) Parallel and (b) series configuration.

inductor, the bypass switch, $S_{s}$, needs to be open when the LCStatCom operates in the inductive region. In the following analysis, both series and parallel compensation strategies are explored in detail.

\section{A. Parallel Compensation}

Parallel compensation is achieved by installing a thyristor switched reactor (TSR) [36]. Once switched into the circuit, a TSR provides a constant inductive current (proportional to voltage) with no explicit control on the magnitude or phase of the current. In the parallel system, the total reactive current when operating in the inductive region can be controlled by varying the capacitive current injected by the LC-StatCom. Therefore, there is no need for utilizing a thyristor controlled reactor (TCR) to achieve variable inductive current [36]-[38]. Whereas the current in a TCR is varied by modifying the applied firing angle, a TSR produces no switching harmonics and has a simpler control system. Furthermore, the LCStatCom provides a faster dynamic response compared to a TCR [39].

The maximum inductive current that the LC-StatCom can generate is lower than 1 p.u for grid voltages higher than 0.62 p.u as described in (6). Therefore, the minimum per-unit current that needs to be supplied by the TSR, $I_{p-\min (p . u)}$, in order to achieve full compensation is

$$
I_{p-\min (p . u)}=1-\left(\frac{1}{V_{g(p . u)}}-V_{g(p . u)}\right),\left(0.62 \leq V_{g(p . u)} \leq 1\right) .
$$

The current supplied by the TSR must be larger than $I_{p-\min (p . u) \text {, }}$ as follows:

$$
\frac{V_{g(p . u)}}{X_{p(p . u)}} \geq I_{p-\min (p . u)} \quad, \quad\left(0.62 \leq V_{g(p . u)} \leq 1\right) .
$$

In (8), $X_{p(p . u)}$ represents the per-unit value of the parallel compensating reactor. The maximum value of $X_{p(p . u)}$ that satisfies (8) is one per-unit. Therefore, a value of one per-unit for the parallel reactor is assumed in the following analysis.

The characteristic of a parallel reactor compensated LCStatCom in the inductive region is

$$
\begin{array}{ll}
0<I_{q(p . u)} \leq \frac{1}{V_{g(p . u)}} & , \quad\left(0.62 \leq V_{g(p . u)} \leq 1\right) \\
0<I_{q(p . u)} \leq V_{g(p . u)}+1 & ,
\end{array} .
$$

The effect of the TSR in reshaping the LC-StatCom V-I characteristic is depicted in Fig. 6. Fig. 6(a), shows the area that needs to be compensated by a TSR. Fig. 6(b), shows the minimum required current for full compensation and the current provided by the TSR. As can be seen from this figure, the minimum required 1 p.u inductor provides excessive current for voltages lower than 1 p.u. This excessive current extends the operating region of the compensated LC-StatCom system beyond 1 p.u current as shown in Fig 6(c).

\section{B. Series Compensation}

In the inductive region, the maximum voltage at which the LC-StatCom is able to operate is lower than 1 p.u as can be seen in Fig. 4. Therefore, from (6), the minimum per-unit voltage that needs to be added by a series compensator, $V_{s-}$ $\min (p . u)$, for full compensation is

$V_{s-\min (p . u)}=1-\frac{-I_{q(p . u)}+\sqrt{I_{q(p . u)}^{2}+4}}{2}$.

The voltage drop across the compensating series reactor must be larger than $V_{s-m i n(p . u)}$,

$X_{s(p . u)} I_{q(p . u)} \geq V_{s-\min (p . u)}$.

In (11), $X_{s(p . u)}$, represents the per-unit value of the series compensating reactor. The minimum value of $X_{s(p . u)}$ that satisfies (11) is 0.5 per-unit. The characteristic of the series TBR integrated LC-StatCom in the inductive region is

$$
0<V_{g(p . u)} \leq \frac{\sqrt{I_{q(p . u)}^{2}+4}}{2} \quad, \quad\left(0<I_{q(p . u)} \leq 1\right) .
$$

The effect of the 0.5 p.u series inductor in reshaping the LC-StatCom characteristic is summarized in Fig. 7. Fig. 7(a), shows the area that needs to be compensated by a series inductor. Fig. 7(b), shows the minimum required voltage for full compensation and the voltage provided by the series inductor. As can be seen from this figure, the selected 0.5 p.u inductor provides some excessive voltage for currents higher than 1 p.u. This excessive voltage extends the operating region of compensated LC-StatCom system beyond 1 p.u voltage as shown in Fig. 7(c).

\section{PROPOSED SYSTEM}

From the previous section it is clear that both series and parallel inductors require the same current rating. Therefore, the option with lower inductance will have a lower energy storage capacity $\left(e_{L}\right)$, according to $e_{L}=0.5 L i^{2}$. Since the series compensation solution has a lower inductance, it is a smaller and cheaper option. Additionally, the series 
$\longleftrightarrow$ Excessive current added by a parallel inductor (After full compensation)

$\leftrightarrow$ Current that needs to be provided by a compensator to achieve symmetric inductive and capacitive operating areas

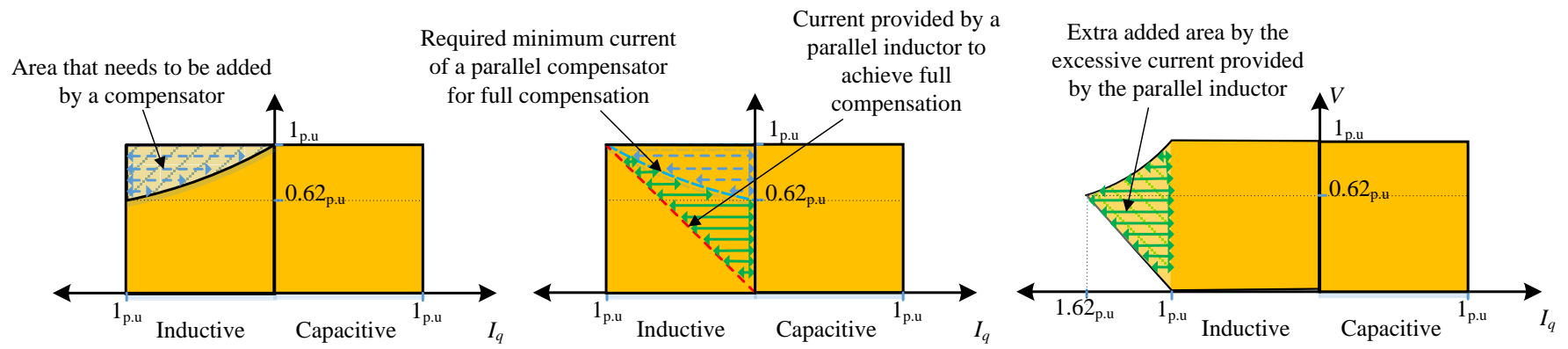

(a)

(b)

(c)

Fig. 6. Parallel compensation. (a) LC -StatCom characteristic and the current required for full compensation, (b) minimum current required for full compensation and the excessive current added by a 1 p.u parallel inductor, and (c) V-I characteristics of a parallel inductor compensated LC-StatCom.
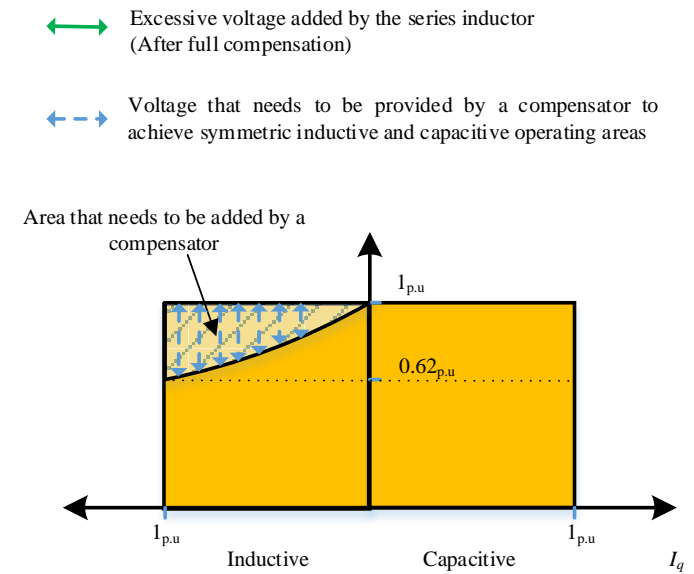

(a)

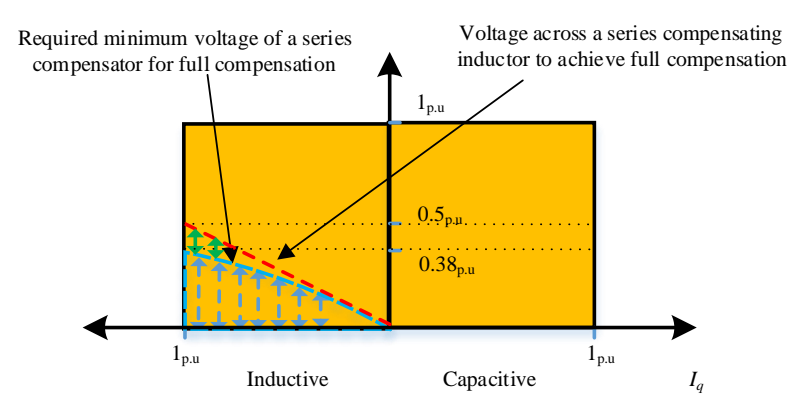

(b)

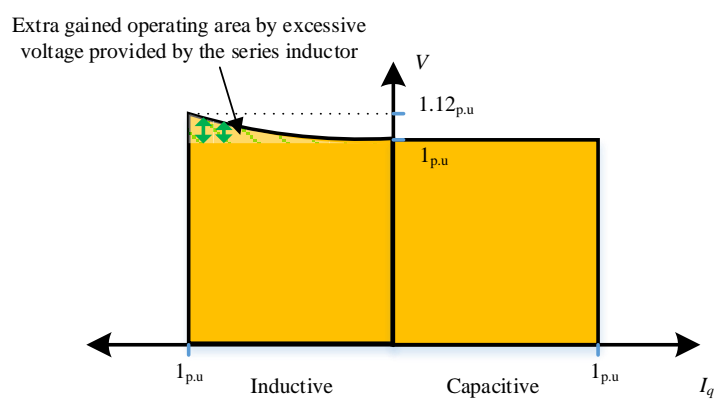

(c)

Fig. 7. Series compensation. (a) LC-StatCom characteristic and the voltage required for full compensation, (b) minimum voltage required for full compensation and the excessive voltage added by a 0.5 p.u series inductor, and (c) V-I characteristics of a series inductor compensated LC-StatCom.

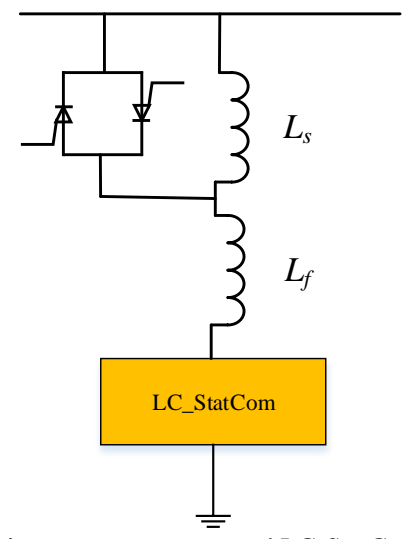

Fig. 8. Proposed series reactor compensated LC-StatCom.

compensation helps to improve current quality because the extra inductance is added in series in this configuration, meaning it helps to filter harmonics produced by the LCStatCom. Therefore, the series configuration is a superior choice.

The proposed compensated LC-StatCom system is shown in Fig. 8. In this figure, $L_{f}$ represents the existing filter inductor in the original LC-StatCom system. As the filter inductor is also placed in series with the LC-StatCom, it helps to reduce the required inductance value of the compensating inductor $L_{s}$.

Fig. 9, shows the effect of the filter inductor on the V-I characteristic of the system. Due to presence of the filter inductor, the LC-StatCom rated voltage needs to be overdesigned to provide nominal capacitive current ( 1 p.u) at 1 p.u voltage. The same over-rating is also required for the conventional CHB StatCom. The voltage over-rating reduces the area that needs to be compensated in the inductive region of the LC-StatCom system, as shown in Fig. 9(a). Fig 9(b), shows the minimum required voltage for full compensation and the voltage provided by the compensating inductor $L_{s}$. The compensating inductor's value can be calculated from

$$
X_{s(p . u)}=1-0.62-2 X_{f(p . u)}
$$

Fig. 9(c), shows the series inductor compensated LC-StatCom characteristic, which includes the effect of the filter inductor. 


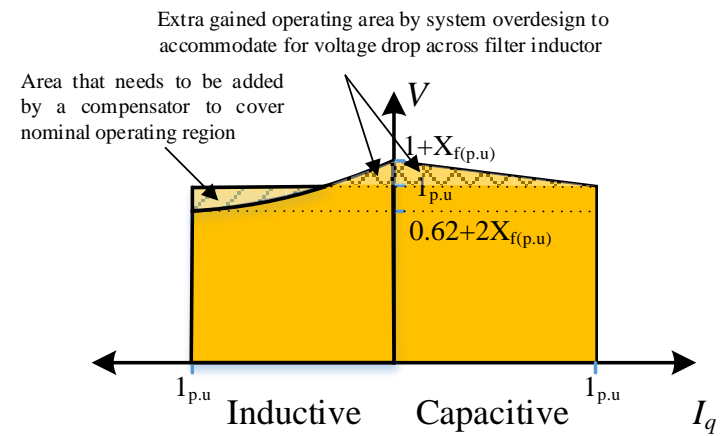

(a)

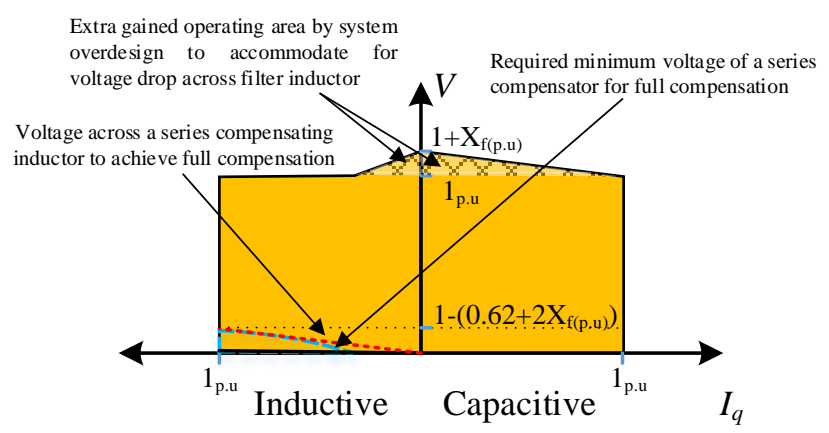

(b)

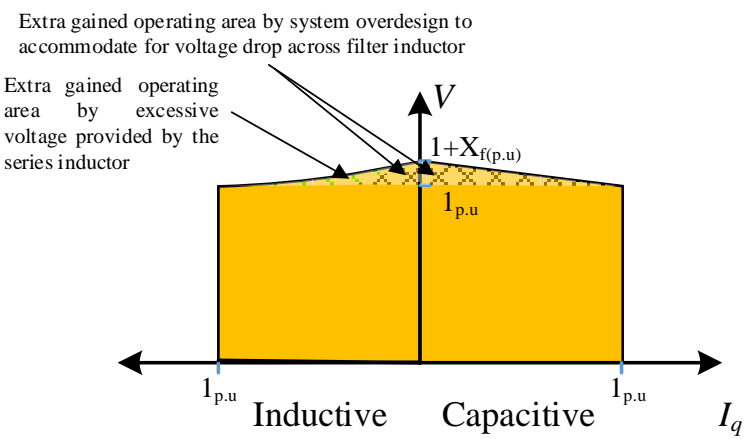

(c)

Fig. 9. Proposed series compensation. (a) Effect of the filter inductor on LC-StatCom characteristic and the voltage required for full compensation, (b) minimum voltage required for full compensation and the excessive voltage added by a series inductor, and (c) V-I characteristics of an LCStatCom with filter inductor and a series TBR compensator.

The effect of $L_{f}$ in reducing the size of $L_{s}$ is multiplied by two as can be seen from (13). The reason is that $L_{f}$ reduces the operating area on the capacitive side but increases the area on the inductive side. Therefore, selecting a larger $L_{f}$ reduces the size of the total reactance $\left(L_{f}+L_{s}\right)$ required in the system. For instance, in the worst case where $X_{f}$ is zero, $X_{s(p . u)}$ is 0.38 , whereas, when $X_{f(p . u)}=0.19, X_{s}$ is zero. Therefore, when $X_{f(p . u)}=0.19$, the total required inductance is the smallest one and there is no need for any additional compensating inductor, which prevents any additional hardware complexity being added to the system. However, the voltage drop on the filter inductor becomes larger with an increasing $X_{f(p . u)}$, which increases the converter's voltage rating to allow operation in the capacitive region. This implies that there is a design tradeoff between the size of the filter inductor (and subsequent size of the compensating inductor) and the converter voltage over- rating. To keep the voltage over-rating in the same range as that required in a conventional CHB StatCom, this paper uses a filter inductance of 0.127 p.u. From (13), this implies use of a series compensating inductor rated at, 0.127 p.u to achieve full compensation.

The bidirectional switch used to connect the series compensating inductor into the circuit can be turned off when the current reaches zero to change the operating mode from capacitive to inductive. Utilization of naturally commutated switches, such as thyristors as shown in Fig .8, ensures the transition will happen at close to zero current where there is approximately zero energy stored in the magnetic field of the filter inductor, which would otherwise produce destructive over-voltages. Thyristors are also relatively cheap, robust, have very low conduction losses, and can be series connected to increase the overall blocking voltage of the switch [40]. Similar to TCRs, a snubber circuit to control the voltage transients during thyristor turn off may be necessary [41], [42]. The current rating of these bypass thyristors is equal to the rating of the semiconductors used within the LC-StatCom. However, their required voltage rating is equal to the maximum voltage drop across the series compensating inductor, which expressed in per unit value is equal to $X_{s(p, u)}$. Therefore, these bypass switches have only a fractional voltage rating compared to the LC-StatCom. Both thyristors share the same gate signal. When the gate signal is activated, the switches start conducting (regardless of current magnitude or direction) to bypass the compensating inductor. On the other hand, when the gate signal is deactivated, the conducting thyristor will remain conducting until the current goes below a certain value (ideally zero), after which the thyristor turns off.

In addition to the abovementioned hardware changes, two sets of different parameters for the current controller need to be used for operation in capacitive and inductive modes as the total inductance value changes. In this paper, the dead-beat current controller uses a discretized version of (1) to produce the ac reference voltages [34]. Therefore, $L$ and $R$ need to be updated when the extra inductor switches in or out. Operation around the boundary of inductive and capacitive regions (zero reactive current) could cause rapid switching of the bypassing thyristors. This unwanted switching can easily be circumvented by introducing a hysteresis band in between the changeover of modes.

\section{EXPERIMENTAL RESULTS}

To experimentally verify the compensated LC-StatCom system, a single-phase seven-level CHB converter was constructed. A photograph and a block diagram of the experimental setup are shown in Fig. 10, and its parameters are given in Table I. The $240 \mathrm{~V}$ grid voltage was reduced to $110 \mathrm{~V}$ and isolated from the grid using a step-down transformer. Three POWEREX PP75B060 single-phase Hbridge converters were connected in series to form the sevenlevel LC-StatCom converter. Phase-shifted PWM was implemented using a DS5203 FPGA module. The PWM signals are transferred to the converter driver board by optical link for galvanic isolation. The feedback signals are 


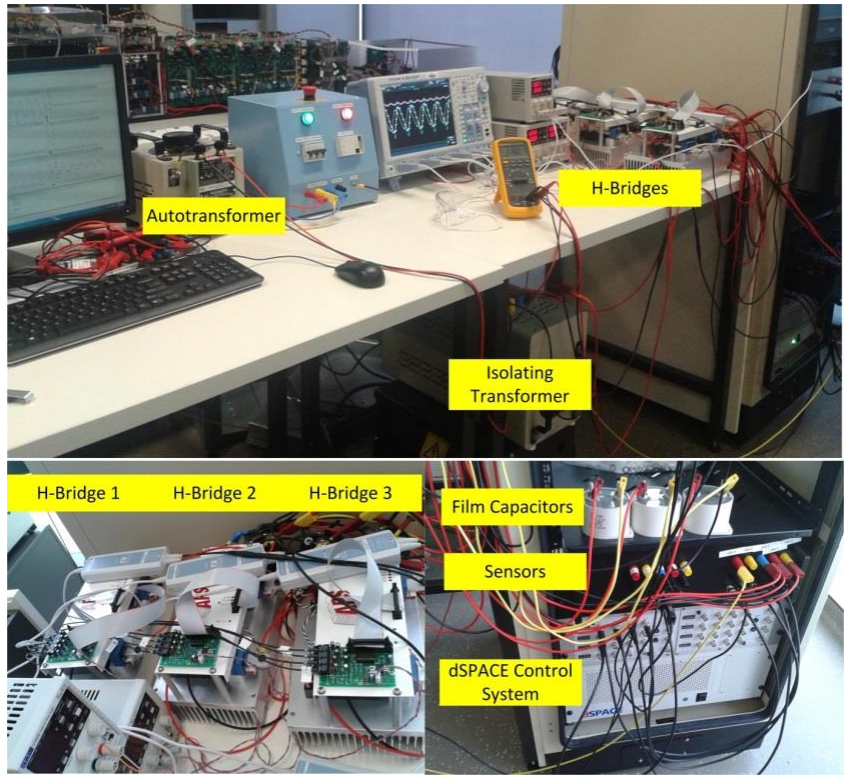

(a)

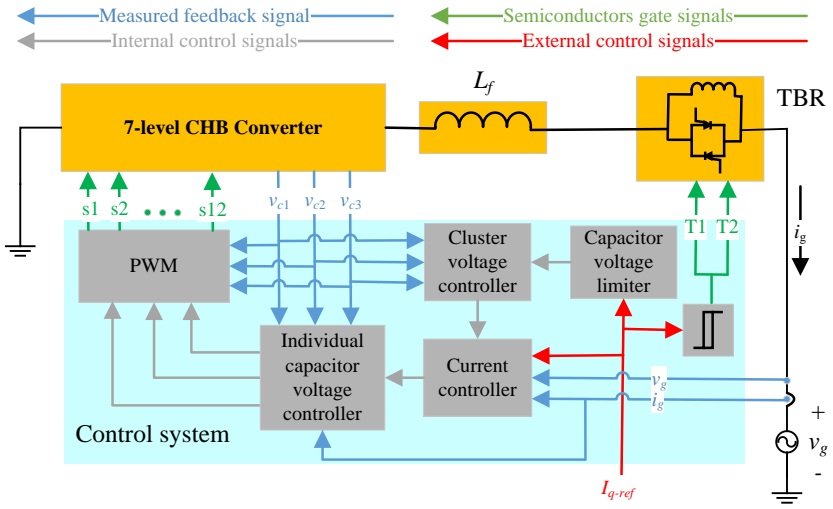

(b)

Fig. 10. (a) Photograph and (b) block diagram of the single-phase, sevenlevel CHB converter LC-StatCom experimental setup.

TABLE I

PARAMETERS OF THE EXPERIMENTAL LC-STATCOM

\begin{tabular}{lll}
\hline \hline Symbol & \multicolumn{1}{c}{ Quantity } & \multicolumn{1}{c}{ Values } \\
& \multicolumn{1}{c}{$110 \mathrm{~V}$} \\
$V_{g n-r m s}$ & Grid voltage $r m s$ value & $260 \mu \mathrm{F}$ \\
$C$ & Capacitance - H-bridge capacitors & $14 \mathrm{mH}(0.127 \mathrm{p} . \mathrm{u})$ \\
$L_{f}$ & Filter inductor & $14 \mathrm{mH}$ \\
$L_{s}$ & Series compensating filter inductor & $2 \mathrm{kHz}$ \\
$f_{s}$ & Switching frequency (per H-bridge) & $180 \mathrm{~V}$ \\
$V_{d c-\text { max }}$ & Maximum voltage on capacitors & $60 \mathrm{~V}$ \\
$V_{d c-\text { min }}$ & Minimum voltage on capacitors & $50 \mathrm{~Hz}$ \\
$f_{g}$ & Grid frequency & $350 \mathrm{VA}$ \\
$S$ & Converter nominal power & $0.5 \Omega$ \\
$R$ & Filter inductor series resistance & $300 \mathrm{rad} / \mathrm{s}$ \\
$w_{v}$ & Bandwidth of the voltage controller & 3 \\
$N$ & Number of H-bridges & \\
\hline \hline
\end{tabular}

routedback to the processor using a DS2004 ADC module. All other control systems were implemented using a dSPACE DS1006 processor board.

In this section, several case studies are performed to demonstrate operation of the compensated LC-StatCom system. In the first case study, response of the system to step changes in reactive current command is investigated. In Fig.

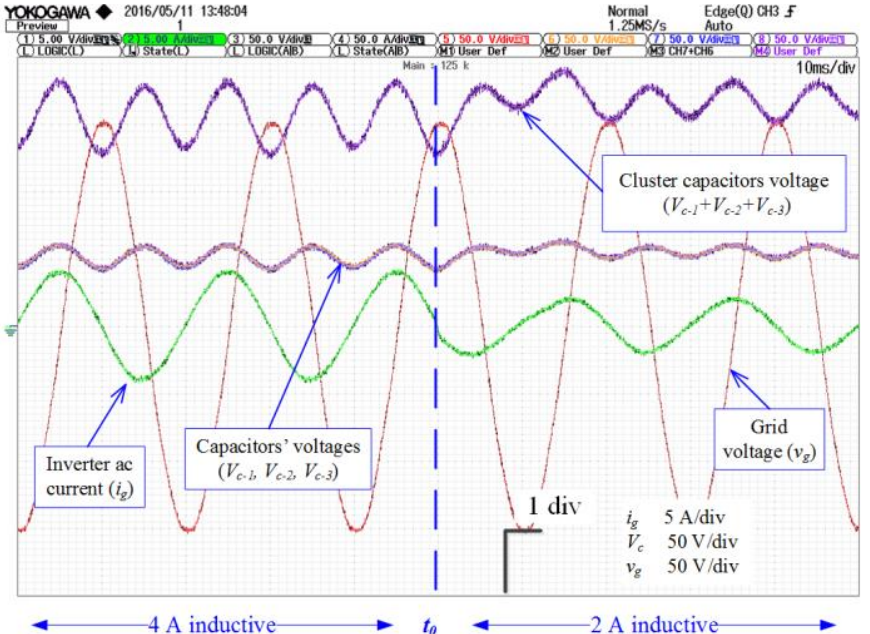

Fig. 11. Operation of compensated LC-StatCom system when the reactive current reference changes from $4 \mathrm{~A}$ inductive to $2 \mathrm{~A}$ inductive at $t_{0}$.

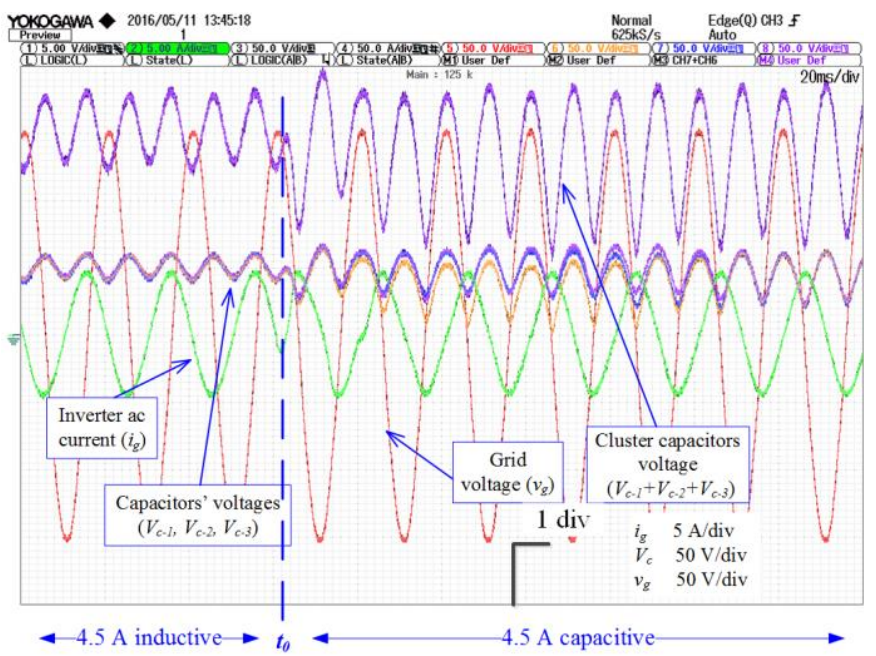

Fig. 12. Operation of the LC-StatCom system when the reactive current reference changes from full inductive to full capacitive at $t_{0}$.

11 operation in the inductive region is shown (the series compensating inductor $L_{s}$ is conducting). In this case, initially the system is providing $4 \mathrm{~A}$ inductive current. At $t_{0}$ the reactive current command changes to $2 \mathrm{~A}$ inductive. Prior to $t_{0}$, a standalone LC-StatCom would not be able to operate in this part of the inductive region because the grid voltage waveform overlaps the cluster voltage waveform. However, by adding the compensating inductor, the converter was able to maintain control over the capacitor voltages and provide the requested inductive current.

In Figs. 12 and 13 more dramatic step changes are investigated, in which the reactive current reference changes from full inductive to full capacitive and vice versa, respectively. The transitions occur at zero current to allow for safe disconnection and connection of the compensating inductor. The voltage across the bypass switch when changing state from on to off is shown in Fig. 14. As can be seen, a transient voltage is generated during the change of modes. This is due to a small nonzero inductor current at the time of switching. It is worthwhile mentioning that in this setup no turn-off snubber was utilized. However, for higher voltage and 


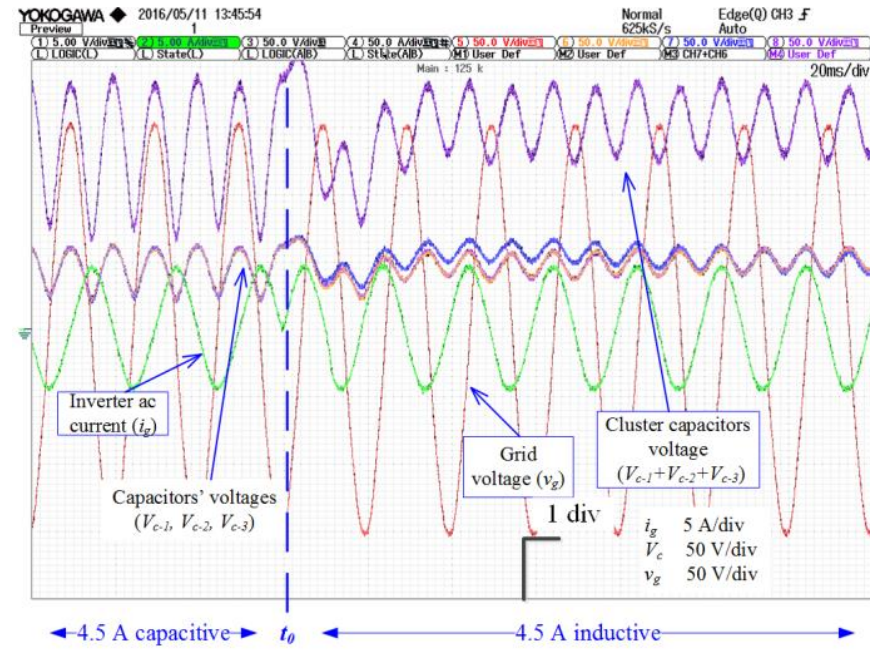

Fig. 13. Operation of the LC-StatCom system when the reactive current reference changes from full capacitive to full inductive at $t_{0}$.

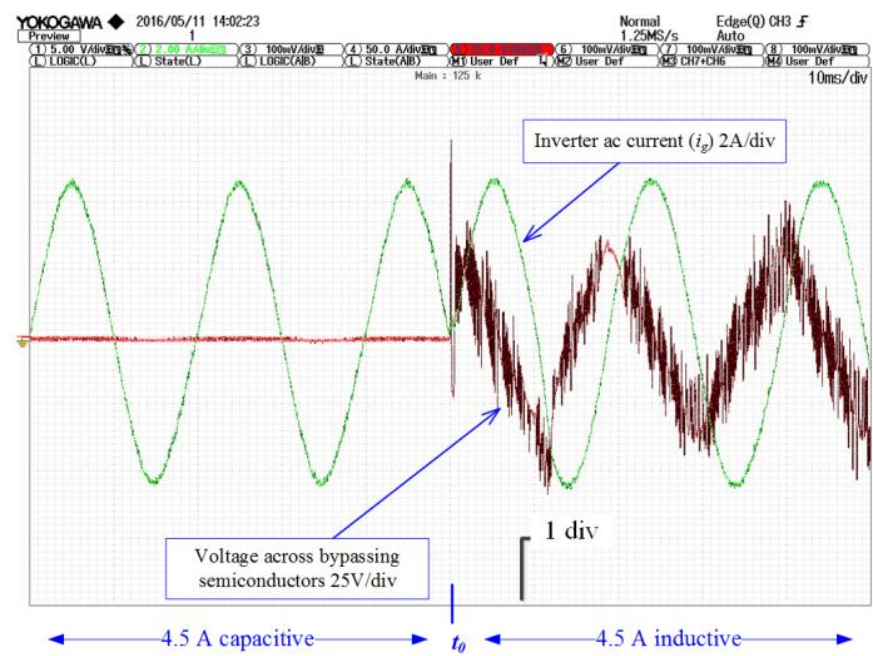

Fig. 14. Voltage across the bypassing semiconductors turning off at $t_{0}$.

current systems a turn-off snubber would be necessary to safeguard the switches from excessive transient voltages.

The current THD remains less than $5 \%$ (4\% in capacitive and $3.5 \%$ in the inductive region). In capacitive region, the filter inductor value is half of that in the inductive region but the current THD remains low because of better utilization of the available voltage levels within the LC-StatCom [34]. As shown in Fig. 15, the capacitor voltage ripple in capacitive region helps to synthesize a sinusoidal ac voltage and the converter utilizes its full capacity (seven-level voltage) in most of the period which results in better current quality. On the other hand, in inductive region, the quality of synthesized ac voltage is lower and the system relies on a higher filter inductor value to reduce the current THD.

Operation under grid voltage fluctuation is demonstrated in Fig. 16. In this experiment, the converter is supplying its rated inductive current. A grid voltage sag is generated by dropping the grid voltage from $110 \mathrm{~V}$ to $75 \mathrm{~V}$ in approximately three cycles. As can be seen, the compensated LC-StatCom's operation was not affected by the transient on the grid voltage. The control system was able to supply the rated current and keep the maximum capacitor voltages constant.

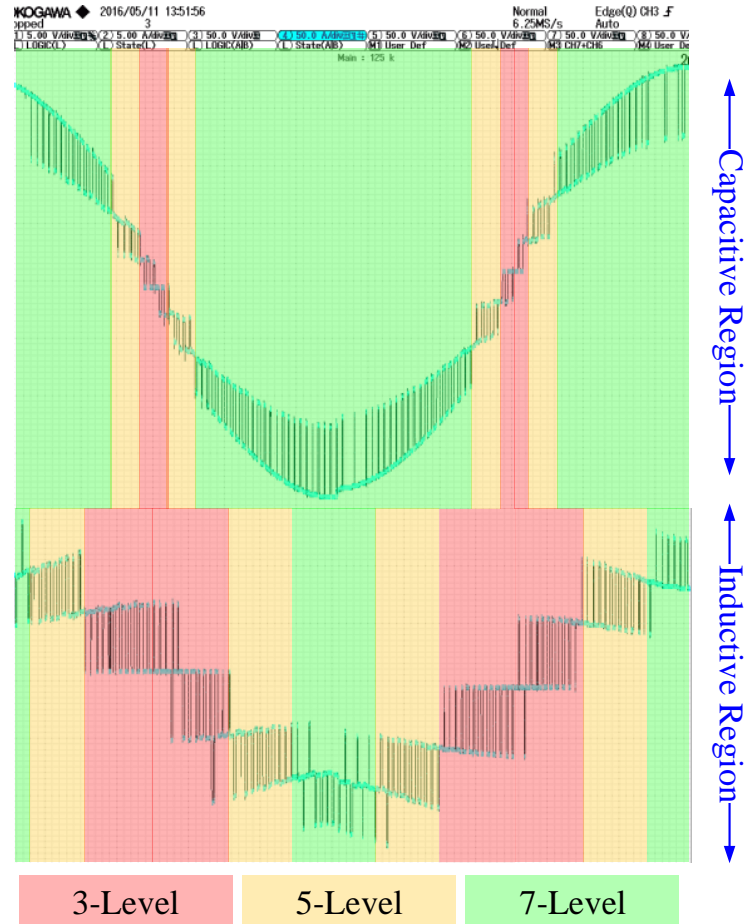

Fig. 15. Demonstration of converter's use of available voltage levels in the LC-StatCom.

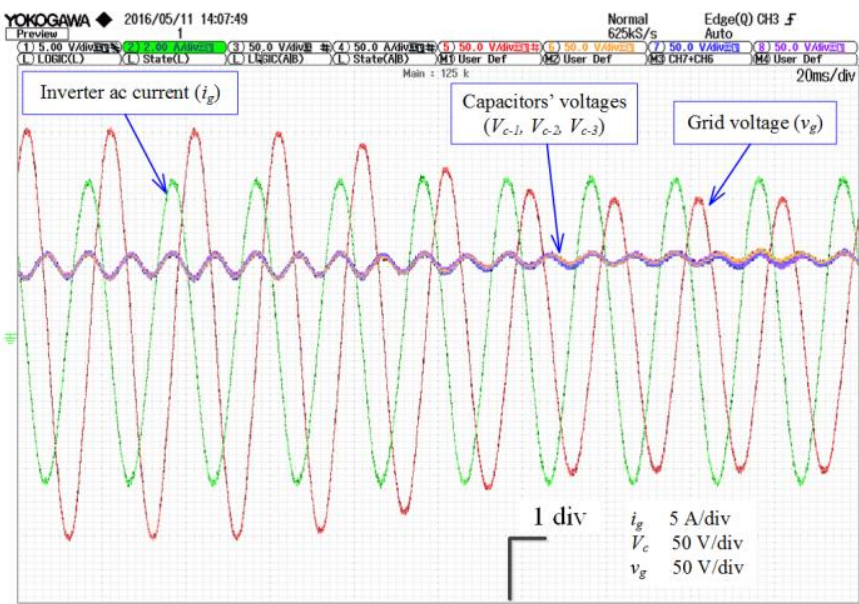

Fig. 16. Operation of the compensated LC-StatCom during grid voltage variation.

The maximum voltage on each capacitor in the proposed system is $60 \mathrm{~V}$. Therefore, the total energy stored in the capacitors is $1.4 \mathrm{~J}$ at peak cluster voltage. In comparison, a conventional CHB StatCom (with maximum 10\% voltage ripple on the capacitors) will have a maximum voltage of $66 \mathrm{~V}$ on each capacitor and the capacitors' size will be approximately $1 \mathrm{mF}$, which results in a total capacitor energy storage requirement of $6.5 \mathrm{~J}$. Therefore, the required capacitor energy storage for the proposed system is approximately $79 \%$ less than a conventional CHB StatCom. In terms of inductor energy storage requirement, the proposed system requires 0.28 $\mathrm{J}$, which is double the size of a conventional CHB-StatCom system due to presence of the series compensating inductor. Therefore, overall the compensated LC-StatCom system 
provides an approximately $75 \%$ reduction in stored energy associated with passive components in the system.

\section{CONCLUSION}

The effects of adding series and parallel passive compensating reactors on the LC-StatCom's operating regions have been investigated. It is shown that a series compensator requires a much smaller inductor size compared to the parallel option. A series compensating reactor is designed to fully compensate the operating range of the LC-StatCom in the inductive region. Effective operation of the proposed concept is demonstrated through experiments using a single-phase seven-level CHB LC-StatCom system. The compensated LCStatCom system was able to operate throughout the full range of inductive and capacitive regions and provide a satisfactory response to transients such as step changes in reactive power and grid voltage variation. The proposed compensated LCStatCom system offers an approximately $75 \%$ saving in overall stored energy compared to a conventional CHB StatCom system.

\section{APPENDIX}

\section{INTRODUCTION TO LC-STATCOM}

Neglecting converter current and grid harmonics, the voltage square on the capacitors will have a pure sinusoidal ripple with double the grid frequency [34].

$\sum_{j=1}^{N} V_{c-j}^{2}(t)=V_{0}^{2} \pm \frac{V I_{g}}{2 \omega C} \cos \left(2 \omega t+2 \alpha_{v}\right)$

In (14), $V$ is the peak value of the generated ac voltage by the inverter and $\alpha_{v}$ is its angle. $V_{0}^{2}$ is the square of the $\mathrm{dc}$ component in the cluster voltage, which is controlled by the cluster voltage controller.

In the LC-StatCom control system, the square of the reference cluster voltage $\left(V_{0 \text {-ref }}^{2}\right)$ is a function of the reactive current reference. The reason for having a variable capacitor voltage reference is to keep the maximum allowed voltage on the capacitors constant. Hence, $V_{0 \text {-ref }}^{2}$ is generated by the CVL block, in Fig.2, to limit the maximum voltage on the capacitors. From (14), the total maximum voltage on the capacitors can be written as

$$
V_{d c-\max }=N \sqrt{\frac{V_{0-r e f}^{2}}{N}+\frac{\left(V_{g} \pm X_{L} I_{q-r e f}\right) I_{q-r e f}}{2 \omega N C}},
$$

were $X_{L}$ is the reactance of $L$ and $I_{q-\text { ref }}$ is the reactive current reference of the LC-StatCom. From (15), in order to have a constant $V_{d c-\max }$, the CVL block generates the reference voltage, $V_{0-r e f}^{2}$ as follows:

$V_{0-r e f}^{2}=\frac{\left(V_{d c-\max }\right)^{2}}{N}-\frac{\left(V_{g} \pm X_{L} I_{q-r e f}\right) I_{q-r e f}}{2 \omega C}$.

The LC-StatCom control system can keep $V_{d c-\max }$ fixed for all values of $I_{q-\text {-ref }}$ within its operational limits. These limits in capacitive and inductive regions are not symmetrical. At full capacitive load, the minimum instantaneous value of the cluster voltage hits its minimum allowed value, $V_{d c-m i n}$. Therefore, from (14) and (16) the nominal reactive power $\left(I_{q n}\right)$ is calculated as

$I_{q n}=\frac{V_{d c-\max }^{2}-V_{d c-\min }^{2}}{V_{g n} N} \frac{\omega C}{1+X_{L(p . u)}}$,

in which, $X_{L(p . u)}$ represents the per-unit value of the filter reactance. In (17), subscript $n$ indicates the nominal value of a quantity. In the following the operational limits of an ideal LC-StatCom are derived.

The LC-StatCom system can work at a given operating point if the instantaneous cluster voltage is higher than the instantaneous grid voltage (absolute value of $v_{g}$ ) for the entire period:

$N V_{c}(t) \geq\left|v_{g}\right|$

In (18), the effect of filter inductor is neglected. Replacing $\left|v_{g}\right|=V_{g}\left|\sin \left(\omega t+\alpha_{v}\right)\right|$ in (18) and squaring each side,

$N V_{c}^{2}(t) \geq \frac{V_{g}^{2}}{2 N}(1-\cos (\theta))$

where $\theta=2 \omega t+2 \alpha_{v}$. For the theoretical limit case in the capacitive region where $V_{d c-m a x}=V_{g n}$, from (14) and (16), (19) can be rewritten as

$\frac{V_{g n}^{2}}{N}-\frac{V_{g} I_{q}}{2 \omega C}(1+\cos (\theta)) \geq \frac{V_{g}^{2}}{2 N}(1-\cos (\theta))$

The condition in (20) is valid for any $0 \leq V_{g}<V_{g n}$ and $0 \leq I_{q}<I_{q n}$ if it is valid for the worst case (nominal operating condition) where $V_{g}=V_{g n}$ and $I_{q}=I_{q n}$. At nominal operating condition, (20) can be rewritten as

$\left(\frac{V_{g n}}{N}-\frac{I_{q n}}{\omega C}\right)(1+\cos (\theta)) \geq 0$.

For the ideal limit case $\left(V_{d c-\max }=V_{g n}, V_{d c-\min }=0\right.$, and $\left.X_{(p . u)}=0\right)$, from (17) $N I_{q n}=\omega C V_{g n}$. Hence, (21) is valid for the whole period $(0<\theta \leq 2 \pi)$. Consequently, the $I-V$ characteristic of the LC-StatCom system is equal to the conventional StatCom system $\left(0 \leq V_{g} \leq V_{g n}, 0 \leq I_{q} \leq I_{q n}\right)$ for the capacitive region.

In the inductive region on the other hand, the following inequality must be satisfied:

$\frac{V_{g n}^{2}}{N}-\frac{V_{g} I_{q}}{2 \omega C}(1-\cos (\theta)) \geq \frac{V_{g}^{2}}{2 N}(1-\cos (\theta))$.

The relation between $V_{g}$ and $I_{q}$ to define the operating region is determined by replacing $\theta=3 \pi / 2$ in (22), resulting in 


$$
I_{q} \leq \frac{V_{g n}^{2}-V_{g}^{2}}{N V_{g}} \omega C \quad, \quad\left(0 \leq V_{g} \leq V_{g n}\right)
$$

By analyzing the inequality in (23), it can be seen that as $V_{g}$ approaches one, $I_{q}$ approaches zero, while below $V_{g} \approx 0.62 V_{g n}$ there is no extra limitation on $I_{q}$. The inductive operating region can therefore be described by

$$
\begin{array}{ccc}
0<I_{q} \leq \frac{V_{g n}^{2}-V_{g}^{2}}{N V_{g}} \omega C & ,\left(0.62 V_{g n} \leq V_{g} \leq V_{g n}\right) \\
0<I_{q} \leq I_{q n} & , \quad\left(0 \leq V_{g}<0.62 V_{g n}\right)
\end{array} .
$$

\section{REFERENCES}

[1] J.S. Lai and F.Z. Peng, "Multilevel converters-a new breed of power converters," IEEE Trans. Ind. Appl., vol. 32, no. 3, pp. 509-517, May/Jun. 1996.

[2] F.Z. Peng, J.S. Lai, J.W. McKeever, and J. VanCoevering, "A multilevel voltage-source inverter with separate DC sources for static VAr generation," IEEE Trans. Ind. Appl., vol.32, no.5, pp.1130-1138, Sep./Oct. 1996.

[3] Y. Liang, and C.O. Nwankpa, "A new type of StatCom based on cascading voltage-source inverters with phase-shifted unipolar SPWM," IEEE Trans. Ind. Appl., vol. 35, no. 5, pp. 1118-1123, Sep./Oct. 1999.

[4] Y. Neyshabouri, H. Iman-Eini, and M. Miranbeigi, "State feedback control strategy and voltage balancing scheme for a transformer-less STATic synchronous COMpensator based on cascaded H-bridge converter," IET Power Electron., vol. 8, no. 6, pp. 906-917, Jun. 2015.

[5] Law Kah Haw, M.S.A. Dahidah, and H.A.F. Almurib, "SHE-PWM cascaded multilevel inverter with adjustable DC voltage levels control for STATCOM applications," IEEE Trans. Power Electron., vol. 29, no. 12, pp. 6433-6444, Dec. 2014.

[6] C.D. Townsend, T.J. Summers, and R.E. Betz, "Impact of practical issues on the harmonic performance of phase-shifted modulation strategies for a cascaded H-bridge StatCom," IEEE Trans. Ind. Electron., vol. 61, no. 6, pp. 2655-2664, Jun. 2014.

[7] C.-T. Lee, B.-S. Wang, S.-W. Chen, S.-F. Chou, J.-L. Huang, P.-T. Cheng, H. Akagi, and P. Barbosa, "Average power balancing control of a STATCOM based on the cascaded H-bridge PWM converter with star configuration," IEEE Trans. Ind. Appl., vol. 50, no. 6, pp. 3893-3901, Nov.-Dec. 2014.

[8] R. Xu, Y. Yu, R. Yang, G. Wang, D. Xu, B. Li, and S. Sui, "A novel control method for transformerless H-bridge cascaded StatCom with star configuration," IEEE Trans. Power Electron., vol. 30, no. 3, pp. 11891202, Mar. 2015.

[9] H. Akagi, S. Inoue, and T. Yoshii, "Control and performance of a transformerless cascade PWM StatCom with star configuration," IEEE Trans. Ind. Appl., vol. 43, no. 4, pp. 1041-1049, Jul.-Aug. 2007.

[10] K. Fujii and R.W. De Doncker, "A novel dc-link voltage control of PWM-switched cascade cell multi-level inverter applied to StatCom," in Proc. Fourtieth IAS Annual Meeting, vol. 2, pp. 961-967, Oct. 2005.

[11] J. de Leon Morales, M.F. Escalante, and M.T. Mata-Jimenez, "Observer for dc voltages in a cascaded H-bridge multilevel StatCom," IET Elect. Power Appl., vol. 1, no. 6, pp. 879-889, Nov. 2007.

[12] L. Yidan, and B. Wu, "A novel dc voltage detection technique in the CHB inverter-based StatCom," IEEE Trans. Power Del., vol. 23, no. 3, pp. 1613-1619, Jul. 2008.

[13] J.A. Barrena, L. Marroyo, M.A.R. Vidal, and J.R.T. Apraiz, "Individual voltage balancing strategy for PWM cascaded H-bridge converter-based StatCom," IEEE Trans. Ind. Electron., vol. 55, no. 1, pp. 21-29, Jan. 2008.

[14] C. Han, A.Q. Huang, Y. Liu, and B. Chen, "A generalized control strategy of per-phase dc voltage balancing for cascaded multilevel converter-based StatCom," in Proc. IEEE PESC, pp. 1746-1752, 17-21 Jun. 2007.

[15] W. Song, and A.Q. Huang, "Fault-tolerant design and control strategy for cascaded H-bridge multilevel converter-based StatCom," IEEE Trans. Ind. Electron., vol. 57, no. 8, pp. 2700-2708, Aug. 2010.
[16] Y. Liu, A.Q. Huang, W. Song, S. Bhattacharya, and G. Tan, "Smallsignal model-based control strategy for balancing individual dc capacitor voltages in cascade multilevel inverter-based StatCom," IEEE Trans. Ind. Electron., vol. 56, no. 6, pp. 2259-2269, Jun. 2009.

[17] N. Hatano and T. Ise, "Control scheme of cascaded H-bridge StatCom using zero-sequence voltage and negative-sequence current," IEEE Trans. Power Del., vol. 25, no. 2, pp. 543-550, Apr. 2010.

[18] C.D. Townsend, T.J. Summers, and R.E. Betz, "Multigoal heuristic model predictive control technique applied to a cascaded H-bridge StatCom," IEEE Trans. Power Electron., vol. 27, no. 3, pp. 1191-1200, Mar. 2012.

[19] C.D. Townsend, T.J. Summers, J. Vodden, A.J. Watson, R.E. Betz, and J.C. Clare, "Optimization of switching losses and capacitor voltage ripple using model predictive control of a cascaded $\mathrm{H}$-bridge multilevel StatCom," IEEE Trans. Power Electron., vol. 28, no. 7, pp. 3077-3087, Jul. 2013.

[20] K. Sano and M. Takasaki, "A transformerless D-StatCom based on a multivoltage cascade converter requiring no dc sources," IEEE Trans. Power Electron., vol. 27, no. 6, pp. 2783-2795, Jun. 2012.

[21] S. Du, J. Liu, J. Lin, and Y. He, "A novel de voltage control method for StatCom based on hybrid multilevel H-bridge converter," IEEE Trans. Power Electron., vol. 28, no. 1, pp. 101-111, Jan. 2013.

[22] B. Gultekin and M. Ermis, "Cascaded multilevel converter-based transmission StatCom: system design methodology and development of a $12 \mathrm{kV} \pm 12 \mathrm{MVAr}$ power stage," IEEE Trans. Power Electron., vol. 28, no. 11, pp. 4930,4950, Nov. 2013.

[23] C.D. Townsend, T.J. Summers, and R.E. Betz, "Issues on the harmonic performance of phase-shifted modulation strategies for a cascaded $\mathrm{H}$ bridge StatCom," IEEE Trans. Ind. Electron., vol. 61, no. 6, pp. 26552664, Jun. 2014.

[24] H. Wang, M. Liserre, and F. Blaabjerg, "Toward reliable power electronics - challenges, design tools and opportunities," IEEE Ind. Electron. Mag., vol. 7, no. 2, pp. 17-26, Jun. 2013.

[25] S. Yang, A. Bryant, P. Mawby, D. Xiang, L. Ran and P. Tavner, "An industry-based survey of reliability in power electronic converters," IEEE Trans. Ind. Appl., vol. 47, no. 3, pp. 1441-1451, May/Jun. 2011.

[26] B. Karanayil, V.G. Agelidis, and J. Pou, "Evaluation of de-link decoupling using electrolytic or polypropylene film capacitors in threephase grid-connected photovoltaic inverters," in Proc. IEEE IECON, pp. 6980-6986, 10-13, Nov. 2013.

[27] H. Wang and F. Blaabjerg, "Reliability of capacitors for dc-link applications in power electronic converters - An overview," IEEE Trans. Ind. Appl., vol. 50, no. 5, pp. 3569-3578, Sep.-Oct. 2014.

[28] H.R. Andersen, R. Tan, and C. Kun, "3-phase ac-drives with passive front-ends with focus on the slim dc-link topology," in Proc. IEEE PESC, pp. 3248-3254, 15-19, Jun. 2008.

[29] R. Maheshwari, S. Munk-Nielsen, and S. Busquets-Monge, "Design of neutral-point voltage controller of a three-level NPC inverter with small dc-link capacitors," IEEE Trans. Ind. Electron., vol. 60, no. 5, pp. 18611871, May 2013.

[30] B. Gültekin, "Cascaded multilevel converter based transmission StatCom: system design methodology and development of a $12 \mathrm{kv} \pm 12$ MVAR power-stage," Ph.D. dissertation, Dept. Elect. Eng., Middle East Technical Univ., Ankara, Turkey, 2012.

[31] H.R. Zeller, "Cosmic ray induced failures in high power semiconductor devices," Microelectronics Reliability, vol. 37, no. 10-11, pp. 17111718, Oct/Nov. 1997.

[32] G. Farivar, B. Hredzak, and V.G. Agelidis, "Reduced capacitance thinfilm H-bridge multilevel StatCom control utilizing an analytic filtering scheme," IEEE Trans. Ind. Electron., vol. 62, no. 10, pp. 6457-6468, Oct. 2015

[33] G. Farivar, C. Townsend, B. Hredzak, J. Pou, and V. Agelidis, "A low capacitance cascaded H-bridge multi-level StatCom," IEEE Trans. on Power Electron., vol. 32, no. 3, pp. 1744-1754, March 2017.

[34] G. Farivar, B. Hredzak, and V.G. Agelidis, "Decoupled control system for cascaded H-bridge multilevel converter based StatCom," IEEE Trans. Ind. Electron., vol. 63, no. 1, pp. 322-331, Jan. 2016.

[35] R. Mohan Mathur and Rajiv K. Varma, "Principles of conventional reactive power compensators," in Thyristor-Based FACTS Controllers for Electrical Transmission Systems, 1, Wiley-IEEE Press, 2002, pp.4092.

[36] S. Rahmani, A. Hamadi, K. Al-Haddad, and L. A. Dessaint, "A combination of shunt hybrid power filter and thyristor-controlled reactor for power quality," IEEE Trans. Ind. Electron., vol. 61, no. 5, pp. 21522164, May 2014. 
[37] A. Luo, Z. Shuai, W. Zhu, and Z. J. Shen, "Combined system for harmonic suppression and reactive power compensation," IEEE Trans. Ind. Electron., vol. 56, no. 2, pp. 418-428, Feb. 2009.

[38] A. Garcia-Cerrada, P. Garcia-Gonzalez, R. Collantes, T. Gomez, and J. Anzola, "Comparison of thyristor-controlled reactors and voltage-source inverters for compensation of flicker caused by arc furnaces," IEEE Trans. Power Delivery, vol. 15, no. 4, pp. 1225-1231, Oct. 2000.

[39] Narain G. Hingorani and Laszlo Gyugyi, "Power semiconductor devices," in Understanding FACTS:Concepts and Technology of Flexible AC Transmission Systems, 1, Wiley-IEEE Press, 2000, pp.3766.

[40] Chang Woo Lee and Song Bai Park, "Design of a thyristor snubber circuit by considering the reverse recovery process," IEEE Trans. Power Electron., vol. 3, no. 4, pp. 440-446, Oct. 1988.

[41] M. O. Popescu, D. Nistor, and C. Popescu, "R-C snubber for thyristor turn-off-a new approach," in Proc. IEEE International Symposium on Industrial Electronics (ISIE), Warsaw, 1996, vol. 1, pp. 505-507.

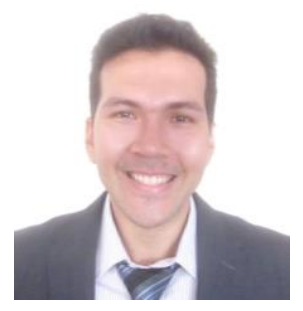

Glen Farivar (S'13) received the B.Sc. degree in electrical engineering from Nooshirvani Institute of Technology, Babol, Iran, in 2008 and the M.Sc degree in power electronics from the University of Tehran, Tehran, Iran in 2011.

$\mathrm{He}$ is currently a $\mathrm{PhD}$ student at the Australian Energy Research Institute, University of New South Wales (UNSW), Sydney, Australia.

His research interests include renewable energy systems, power convertors, FACTS devices, and hybrid electric vehicles.

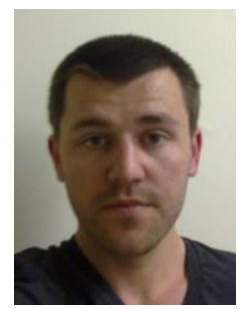

Christopher D. Townsend (S'09-M'13) received the B.E. (2009) and Ph.D. (2013) degrees in electrical engineering from the University of Newcastle, Australia.

Between 2012 and 2016 he spent four years working with both ABB Corporate Research, Västerås, Sweden and The University of New South Wales, Australian Energy Research Institute, Sydney, Australia. He is currently working as a post-doctoral researcher at the University of Newcastle, Australia. His current research interests include topologies and modulation strategies for multi-level converters. He is a member of the Power Electronics and Industrial Electronics Societies of the IEEE.

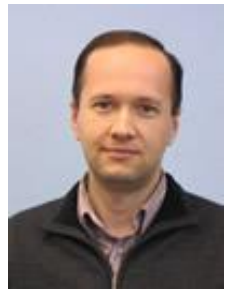

Branislav Hredzak (M'98-SM'13) received the B.Sc./M.Sc. degree from the Technical University of Kosice, Slovak Republic, in 1993 and the Ph.D. degree from Napier University of Edinburgh, UK, in 1997, all in Electrical Engineering.

$\mathrm{He}$ was as a Lecturer and a Senior Researcher in Singapore from 1997 to 2007. $\mathrm{He}$ is currently a Senior Lecturer in the School of Electrical Engineering and Telecommunications, The University of New
South Wales, Sydney, NSW, Australia. His current research interests include hybrid storage technologies and advanced control systems for power electronics and storage systems.

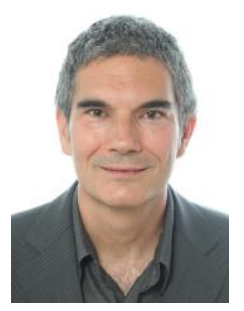

Josep Pou (S97-M03-SM13-F16) received the B.S., M.S., and Ph.D. degrees in electrical engineering from the Technical University of Catalonia (UPC), Catalonia, Spain, in 1989, 1996, and 2002, respectively.

In 1990, he joined the faculty of UPC as an Assistant Professor, where he became an Associate Professor in 1993. From February 2013 to August 2016, he was a Professor with the University of New South Wales (UNSW), Sydney, Australia. He is currently an Associate Professor with the Nanyang Technological University, Singapore. From February 2001 to January 2002, and February 2005 to January 2006, he was a Researcher at the Center for Power Electronics Systems, Virginia Tech, Blacksburg. From January 2012 to January 2013, he was a Visiting Professor at the Australian Energy Research Institute, UNSW, Sydney. Since 2006, he has collaborated with Tecnalia Research \& Innovation as a research consultant. He has authored more than 220 published technical papers and has been involved in several industrial projects and educational programs in the fields of power electronics and systems. His research interests include modulation and control of power converters, multilevel converters, renewable energy generation, energy storage, power quality, and HVDC transmission systems.

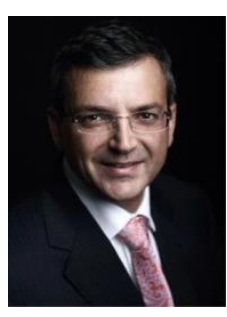

Vassilios G. Agelidis (S'89-M'91-SM'00F'16) was born in Serres, Greece. He received the B.Eng.degree in electrical engineering from the Democritus University of Thrace, Thrace, Greece, in 1988, the M.S. degree in applied science from Concordia University, Montreal, QC, Canada, in 1992, and the Ph.D. degree in electrical engineering from Curtin University, Perth, Australia, in 1997. He has worked at Curtin University (1993-1999), University of Glasgow, U.K. (2000-2004), Murdoch University, Perth, Australia (2005-2006), the University of Sydney, Australia (2007-2010), and the University of New South Wales (UNSW), Sydney, Australia (2010-2016). He is currently a professor at the Department of Electrical Engineering, Technical University of Denmark.

Dr. Agelidis received the Advanced Research Fellowship from the U.K.'s Engineering and Physical Sciences Research Council in 2004. He was the Vice-President Operations within the IEEE Power Electronics Society from 2006 to 2007. He was an AdCom Member of the IEEE Power Electronics Society from 2007 to 2009 and the Technical Chair of the 39th IEEE Power Electronics Specialists Conference, Rhodes, Greece, 2008. 